\title{
Cholesterol absorption by the gall bladder
}

\author{
P E Ross, A N Butt, C Gallacher
}

\begin{abstract}
Model and real biles were used to investigate factors influencing cholesterol and dextran (70 000 molecular weight) absorption by the gall bladder. Cholesterol absorption was proportional to cholesterol concentration when real bile was used, but model biles showed maximal absorption at cholesterol saturation. Reduction of temperature reduced cholesterol absorption and serosal secretion, but had little effect on dextran absorption. This indicates differences in uptake where cholesterol undergoes passive diffusion but dextran is taken up by fluid-phase endocytosis. Model bile prepared with a single bile salt showed lowest cholesterol uptake from cholate bile, but there was no difference in serosal secretion. Dextran uptake was also lowest from cholate bile, although serosal secretion was highest.
\end{abstract}

These results show that an increase in the biliary content of dihydroxy bile salts increases gall bladder permeability to both hydrophobic and hydrophilic molecules and may lead to the accumulation of lipids in the mucosa, as seen in cholesterolosis.

Cholesterol uptake by the intestine is predominantly a passive process related to the high intraluminal concentration and facilitated by micelle formation with the bile salts and phospholipids secreted in bile. ${ }^{1}$ The embryonal relation between gall bladder and intestine, together with the exposure of gall bladder epithelium to high cholesterol, bile salt, and phospholipid concentrations, suggest that a similar process might be found in gall bladders. This is supported by the similarity in histochemical demonstration of lipids in gall bladder epithelium at cholecystectomy and in intestinal epithelium after lipid challenge, ${ }^{2}$ and by the similar values for lipid uptake shown in the gall bladders and small intestines of guinea pigs. ${ }^{3}$

Cholesterol absorption has been reported in guinea pig ${ }^{4}$ and human ${ }^{5}$ gall bladders, and a recent report from our laboratory showed a $30 \%$ inhibition of cholesterol absorption by cyanide. ${ }^{6}$ This is similar to the $40 \%$ reduction reported for intestine, ${ }^{7}$ part of the evidence for which led these authors to propose an energy dependent process that contributes to intestinal cholesterol absorption.

In gall bladders this may be non-specific endocytosis; an early electron microscopy report suggested that cholesterol may be taken up by this process. ${ }^{8}$ More recently we have used cationised ferritin to show endocytosis in gall bladder epithelium. ${ }^{9}$ Dextran (70 000 molecular weight) is also transported across gall bladder mucosa in vesicles ${ }^{10}$ and, as serosal secretion of lipid is reduced by the microtubule inhibitor colchicine, ${ }^{3}$ these vesicles probably have a role in lipid uptake by the gall bladder. This study was designed to investigate some of the factors which may influence this uptake.

\section{Methods}

Cholesterol (99\% + pure), sodium bile salts, and $\mathrm{L} \alpha$ phosphatidylcholine (egg yolk type IX-E) were obtained from Sigma Chemicals, Poole, Dorset; all other chemicals were analytical grade, supplied by BDH Ltd, Poole, Dorset, who also supplied Merck Kieselgel $60 \mathrm{G}$ for thin-layer chromatography. The scintillation fluid used was Hionic Fluor from Canberra Packard, Pangbourne, Berkshire while both $\left[4-{ }^{14} \mathrm{C}\right]$-cholesterol and $\left[{ }^{3} \mathrm{H}\right]-$ dextran (70 000 daltons) were supplied by Amersham International, Amersham, Buckinghamshire; the purity was confirmed before and during use. Krebs-Ringer bicarbonate buffer ( $\mathrm{pH} 7.4$ ) with added glucose KRBG was prepared, as previously described. ${ }^{11}$

Gall bladders were received within $10 \mathrm{~min}$ utes of ligation of the cystic artery at cholecystectomy for the usual clinical indications. They were taken, still ligated, to the Pathology Department where they were measured, opened, and the presence of bile and stones recorded before two specimens of gall bladder wall were taken for histopathological assessment. The remainder of the gall bladder was placed in oxygenated saline at room temperature and taken to the Department of Medicine, together with bile, for use in uptake experiments. This procedure took about 10 minutes. The gall bladder wall was gently washed with saline to remove adherent bile and sludge, and then serosal tissue was removed from portions of the fundus by blunt dissection. Ulcerated tissue was not used. In an earlier study tissue viability throughout the duration of the experiment was shown by histochemistry, transmural potential difference, and tissue oxygen consumption using a Clark oxygen electrode. ${ }^{6}$ These data confirmed tissue viability for over two hours, which exceeded the one hour duration of these experiments. In the present experiments $\mathrm{Na}^{+}$ or $\mathrm{K}^{+}$adenosine triphosphatase activity was used to show tissue viability. 


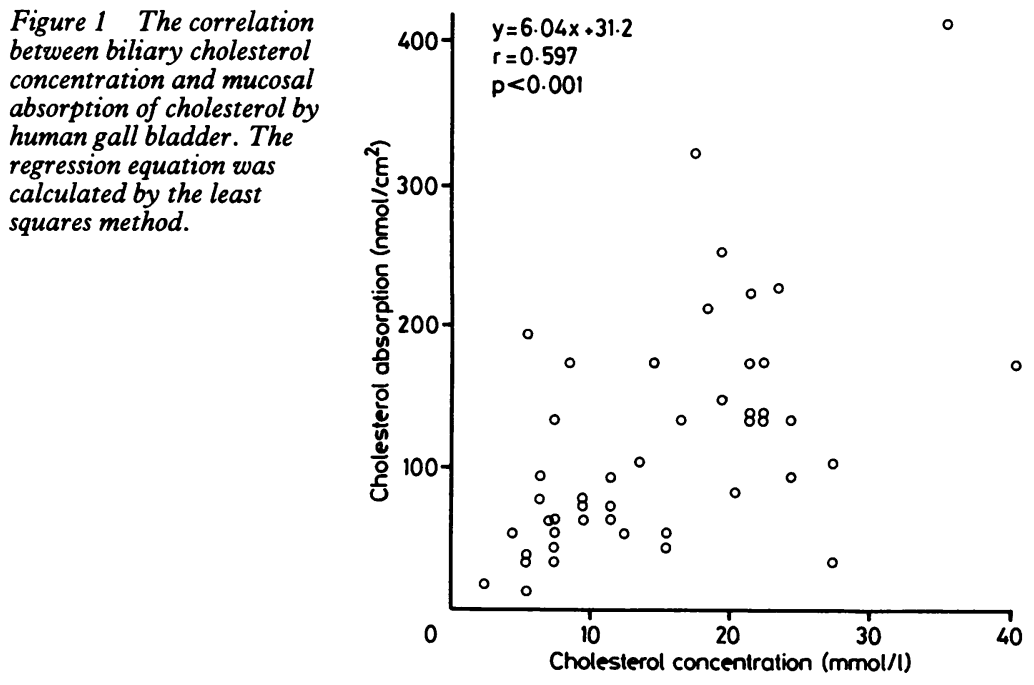

PREPARATION OF BILE

Artificial bile was prepared as described in a previous report from this laboratory, ${ }^{6}$ using a glycine:taurine ratio of 3:1 and a phospholipid to bile salt molar ratio of $0 \cdot 2$. To study the effect of individual bile salts the mixture of bile salts was replaced by the single bile salt, although all other constituents of this artificial bile were unchanged. Cholesterol was added to give a lithogenic index of $1 \cdot 0^{12}$ and after reconstitution in sodium chloride $(0 \cdot 154 \mathrm{M})$ the $\mathrm{pH}$ was adjusted to 7.5 and the bile heated at $80^{\circ} \mathrm{C}$ for one hour. The isotropic solution was filtered through a $0.22 \mu \mathrm{m}$ filter (Millipore SA, Molshein, France) and the optically clear micellar suspensions kept at $37^{\circ} \mathrm{C}$ until used.

Gall bladder bile was used within 30 minutes of collection, either undiluted or diluted 1:5 with sodium chloride solution $(0 \cdot 154 \mathrm{M})$. Immediately before beginning the experiment tracer $\left[{ }^{3} \mathrm{H}\right]$-dextran and $\left[{ }^{14} \mathrm{C}\right]-$ cholesterol $(37 \mathrm{kBq} / \mathrm{ml})$ were added to give a ${ }^{3} \mathrm{H} /{ }^{14} \mathrm{C}$ ratio between $5: 1$ and $10: 1{ }^{13}$ Artificial biles were mixed thoroughly before use; gall bladder biles were homogenised with a hand driven Teflon glass homogeniser.

\section{CHOLESTEROL ABSORPTION}

The modified flux chamber has been described previously. ${ }^{6}$ Briefly, two perspex chambers act as independent compartments separated by gall bladder tissue $\left(0.2 \mathrm{~cm}^{2}\right)$, allowing the two surfaces of the gall bladder to be bathed independently. The luminal side was exposed to $1 \mathrm{ml}$ of real or model bile while the serosal side contacted $2 \mathrm{ml}$ of

Table 1 Regression analysis of factors influencing cholesterol and dextran absorption by gall bladder mucosa

\begin{tabular}{llll}
\hline Absorption & Factor & Gradient & Correlation \\
\hline Cholesterol nmol $/ \mathrm{cm}^{2} / \mathrm{h}$ & Cholesterol $(\mathrm{mmol} / \mathrm{l})$ & +6.04 & $0.597^{\star \star \star}$ \\
& Dry weight $(\mathrm{g} / \mathrm{dl})$ & +6.04 & $0.336^{\star}$ \\
& Sodium (meq/l) & +0.56 & 0.188 \\
& & & -1470 \\
Dextran dpm & Cholesterol (mmol/l) & -626 & $-0.5462^{\star \star}$ \\
& Dry weight $(\mathrm{g} / \mathrm{dl})$ & -394 & $-0.478^{\star}$ \\
\hline
\end{tabular}

$\star \star \star \mathrm{p}=<0.001 ;{ }^{\star \star} \mathrm{p}<0.005 ;{ }^{\star} \mathrm{p}<0.05$

For clarity, intercept values are not shown.
KRBG, which was oxygenated by bubbling with $\mathrm{O}_{2} / \mathrm{CO}_{2}(95 / 5)$. The entire chamber was surrounded by a water jacket which maintained the chamber contents at a constant temperature. After one hour the experiment was stopped, the bile and KRBG retained, and the tissue removed, rinsed for five seconds in cold saline and blotted on dry filter paper for two seconds. The tissue was then heated at $110^{\circ} \mathrm{C}$ in $0.5 \mathrm{ml}$ of $0.75 \mathrm{M} \mathrm{NaOH}$ until dissolved. The solution was cooled and the $\mathrm{pH}$ adjusted to $7 \cdot 0$ before the radioactivity content was measured.

\section{BILE COMPOSITION}

An aliquot of bile was removed for measurement of the dry weight by heating $0 \cdot 1$ $\mathrm{ml}$ at $110^{\circ} \mathrm{C}$ in an oven for two hours. Biliary lipids were extracted ${ }^{14}$ and assayed by either spectrophotometry (phospholipid ${ }^{15}$ ) or gasliquid chromatography (cholesterol and bile acids $^{16}$ ). Biliary sodium was quantitated by flame photometry after filtration through a $0.22 \mu \mathrm{m}$ filter.

\section{MEASUREMENT OF RADIOACTIVITY}

Samples were counted in a Packard 2200CA TriCarb liquid scintillation analyser using full spectrum dual label quench correction based on two quench curves, one prepared with digested tissue and the other with bile added to $4.5 \mathrm{ml}$ of hionic fluor containing standard tracer.

\section{Results}

A total of 48 gall bladders were studied using bile found in each gall bladder at cholecystectomy, and in each case both cholesterol and dextran were absorbed by the mucosal surface. Biliary cholesterol concentration was the major determinant of cholesterol absorption, showing a highly significant correlation ( $p<0.001$, fig 1). Bile dry weight, an index of gall bladder function, showed a weak correlation with cholesterol absorption ( $\mathrm{r}=0.336, \mathrm{p}=0.03)$ (table 1), which is similar to that between dry weight and biliary cholesterol concentration $(\mathrm{r}=0.315, \mathrm{p}=0.042)$, although sodium concentration was unrelated (table 1). Cholesterol absorption was independent of the lithogenic index and showed no sign of a maximum as the bile became supersaturated with cholesterol (fig 2). Although cholesterol and dextran are both absorbed, there are clear differences between these molecules. Firstly, there was no significant correlation between the rates of absorption of both molecules, and dextran absorption is negatively correlated with all factors considered in this study (table 1), significantly so with biliary cholesterol concentration $(p=0.004)$ and sodium concentration $(\mathrm{p}=0.036)$.

When absorption studies were carried out at $20^{\circ} \mathrm{C}$, cholesterol absorption was reduced to $50^{\circ} \%$ of the values at $37^{\circ} \mathrm{C}(\mathrm{p}=0.004)$, but further reduction to $4^{\circ} \mathrm{C}$ produced only a small decrease from the $20^{\circ} \mathrm{C}$ values (table 2). Serosal secretion also showed a $50 \%$ reduction at $20^{\circ} \mathrm{C}$ 


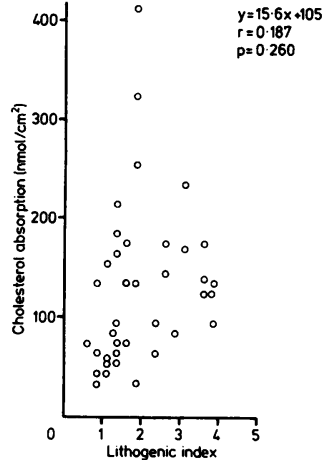

Figure 2 The correlation between lithogenic index and mucosal absorption of cholesterol by human gall bladder. The regression equation was calculated by the least squares method. $(p=0.005)$, but values could not be measured at $4^{\circ} \mathrm{C}$ because the scintillation counts were too low for reliable double isotope counting. Dextran absorption was also reduced at lower temperatures, but the reduction was not significant at $20^{\circ} \mathrm{C}$, and just significant at $4^{\circ} \mathrm{C}$. The serosal secretion, however, was significantly reduced at both temperatures. These results are shown in table 2.

When model biles comprising a single bile acid species were used to assess their effect on absorption of cholesterol and dextran there were differences in the effect of the different bile acids. With chenodeoxycholic acid cholesterol uptake was greater than for deoxycholic and significantly greater than for cholate $(p<$ 0.01 ), although serosal secretion was not different. Conversely, dextran uptake was not significantly affected by the different bile acids studied, but serosal secretion of dextran was higher with cholate model bile, and significantly higher than deoxycholate $(p=0.042)$, but not chenodeoxycholate $(p=0.068)$. These results are shown in table 3.

\section{Discussion \\ In an earlier study from this laboratory ${ }^{4}$ gall bladders were shown to absorb significant amounts of biliary cholesterol, and, using model biles, the rate of absorption correlated with biliary saturation rather than biliary cholesterol concentration. ${ }^{6}$ This absorption showed a linear increase as saturation increased, reaching a maximum when model bile became saturated with cholesterol (litho- genic index $>1 \cdot 0$ ). Neither cholesterol uptake nor serosal secretion was affected by the degree of chronic cholecystitis ${ }^{6}$ which shows that the uptake measured is not a function of the disease process. Metabolic inhibitors and colchicine, the microtubule inhibitor, reduce tissue uptake and serosal secretion, ${ }^{3}$ indicating that the serosal secretion is not simply a product of}

Table 2 Effect of temperature on mucosal uptake and serosal secretion of cholesterol and dextran 70000 by human gall bladder mucosa

\begin{tabular}{|c|c|c|c|c|c|}
\hline Absorption & $\begin{array}{l}\text { Temperature } \\
{ }^{\circ} \mathrm{C}\end{array}$ & Mucosal uptake & $N$ & Serosal secretion & $N$ \\
\hline $\begin{array}{l}\text { Cholesterol } \\
\mathrm{nmol} / \mathrm{cm}^{2} / \mathrm{h}(\mathrm{SEM})\end{array}$ & $\begin{array}{r}37 \\
20 \\
4\end{array}$ & $\begin{array}{l}133(28 \cdot 8) \\
65 \cdot 9(8 \cdot 1)^{\star} \\
59 \cdot 0(11 \cdot 9)^{\star}\end{array}$ & $\begin{array}{l}27 \\
18 \\
14\end{array}$ & $\begin{array}{l}0.7(0.25) \\
0.29(0.17)\end{array}$ & $\begin{array}{l}13 \\
13\end{array}$ \\
\hline $\begin{array}{l}\text { Dextran } \\
\mathrm{dpm} / \mathrm{cm}^{2} / \mathrm{h}(\mathrm{SEM})\end{array}$ & $\begin{array}{r}37 \\
20 \\
4\end{array}$ & $\begin{array}{l}4645(448) \\
4143(404) \\
3391(330)\end{array}$ & $\begin{array}{l}28 \\
28 \\
28\end{array}$ & $\begin{array}{l}666(85) \\
354(59)^{\star} \\
196(22)^{\star \star}\end{array}$ & $\begin{array}{l}28 \\
28 \\
28\end{array}$ \\
\hline
\end{tabular}

Table 3 Effect of individual bile acids on mucosal uptake and serosal secretion of cholesterol and dextran

\begin{tabular}{lllllr}
\hline Absorption & Bile acid & $\begin{array}{l}\text { Mucosal } \\
\text { uptake }\end{array}$ & $N$ & $\begin{array}{l}\text { Serosal } \\
\text { secretion }\end{array}$ & $N$ \\
\hline Cholesterol & Cholate & $59 \cdot 7(13 \cdot 6)$ & 10 & $15 \cdot 6(2 \cdot 2)$ & 10 \\
nmol/cm $/ \mathrm{h}(\mathrm{SEM})$ & $\begin{array}{l}\text { Deoxycholate } \\
\text { Chenodeoxycholate }\end{array}$ & $\begin{array}{l}93 \cdot 4(22 \cdot 2) \\
127 \cdot 0(30 \cdot 8) \star \star\end{array}$ & 10 & $11 \cdot 2(2 \cdot 3)$ & 12 \\
& Chextran & $11785(1533)$ & 19 & $859(223)$ & 19 \\
dpm $/ \mathrm{cm}^{2} / \mathrm{h}(\mathrm{SEM})$ & $\begin{array}{l}\text { Cholate } \\
\text { Deoxycholate }\end{array}$ & $20405(6171)$ & 19 & $340(54)^{\star}$ & 19 \\
& Chenodeoxycholate & $17575(4575)$ & 18 & $387(85)$ & 18 \\
\hline
\end{tabular}

${ }^{\star} \mathrm{p}=<0.05 ;{ }^{\star \star} \mathrm{p}<0.001$

Each bile acid was used individually to prepare a model bile for investigation passive cholesterol exchange between bile and mucosa and mucosa and serosal fluid.

This study has extended those results, showing that cholesterol uptake is significantly correlated with biliary concentration but independent of lithogenic index (figs 1 and 2) when gall bladder biles are used. Absorption from model biles correlated with lithogenic indices of $<1.0$ in the earlier study because the lithogenic index was changed by varying the cholesterol concentration; in gall bladders bile concentrations of all three lipids vary to give different lithogenic indices. Supersaturated model biles were unstable and there was probably little increase in the cholesterol concentration available for absorption, which would explain the maximum observed at a lithogenic index of 1.0 .

Biliary dry weight is an index of gall bladder function and the correlation between dry weight and cholesterol absorption could be interpreted as indication of the importance of gall bladder function for cholesterol absorption. Cholesterol concentration increases, however, as biliary dry weight increases, and the correlation between dry weight and cholesterol absorption is probably a consequence of the correlation between cholesterol concentration and dry weight. The prime importance of cholesterol concentration as a determinant of absorption was confirmed by duplicating studies with the same bile but different gall bladder samples. Absorption was similar for the same bile samples despite differences in the extent of gall bladder disease (results not shown), supporting our earlier finding with model biles.

This dependence on cholesterol concentration is similar to the passive absorption of cholesterol seen in the intestine. ${ }^{1}$ Cyanide inhibits cholesterol absorption by $30 \%$, however, suggesting that this fraction constitutes energy dependent endocytosis shown in the gall bladder. ${ }^{9}$ Similar results were interpreted as evidence of an energy dependent transport of cholesterol in intestine. ${ }^{7}$

Uptake of dextran shows pronounced differences from cholesterol (table 1), most strikingly as the significant negative correlation with biliary cholesterol concentration $(r=-0.546 ; p<0.005)$. A significant negative correlation is also observed with sodium concentration but not dry weight, indicating that dextran uptake is reduced at high cholesterol and sodium ion concentrations but this is not simply a function of bile solid content. Water absorption associated with active sodium transport may aid passage of hydrophilic compounds across the unstirred water layer, a possibility which could be tested by simultaneous measurement of sodium (or water) flux and dextran absorption.

There was a reduction of $50 \%$ in cholesterol absorption at $20^{\circ} \mathrm{C}$ and a slightly greater reduction at $4^{\circ} \mathrm{C}$. Both values were greater than the $30 \%$, possibly representing endocytosis and suggesting that the lower temperatures may reduce passive diffusion of cholesterol into the membrane in addition to reducing endocytosis. Serosal secretion was also significantly reduced 
at $20^{\circ} \mathrm{C}$, but reliable results could not be obtained at $4^{\circ} \mathrm{C}$ because at this temperature the $\left[{ }^{14} \mathrm{C}\right]$ secreted is too low for reliable double isotope counting. The reduced temperature is unlikely to have changed the micellar structure of the bile as the critical micellar temperature is below $0{ }^{\circ} \mathrm{C} .{ }^{17}$ Unlike cholesterol, dextran uptake is not significantly reduced at lower temperatures, although serosal secretion is (table 2). This is in keeping with reduced internalisation of endocytotic vesicles following relatively unchanged binding to the apical membrane.

Intestinal studies have shown that individual bile salts have characteristic properties which may influence lipid absorption by the gall bladder. For example, taurochenodeoxycholate has no effect on intestinal cholesterol absorption in the bile fistula of rats but taurocholate increases intestinal cholesterol absorption. ${ }^{18}$ Model biles prepared with a single conjugated bile acid showed that cholesterol uptake was greatest with chenodeoxycholate bile and significantly greater than with cholic acid, the trihydroxy bile salt. Despite this difference in cholesterol uptake serosal secretion did not differ, indicating either reduced uptake or enhanced intracellular transport in cholate bile compared with chenodeoxycholate. This agrees with the findings of an earlier study of intestinal cholesterol absorption $^{19}$ which suggested that micellar solubilisation is essential for uptake, but cholic acid is associated with the greatest transfer of cholesterol into lymph, possibly due to enhanced intracellular transport. This is supported by the data on dextran uptake because, like cholesterol, serosal secretion of dextran is higher with cholate model bile although mucosal content is lower. Dihydroxy bile salts seem to potentiate diffusion of cholesterol and dextran to the apical membrane, perhaps by disruption of the mucous layer, but reduce intracellular vesicular transport. Cholate is less efficient in promoting the luminal diffusion of these disparate molecules but maintains or enhances intracelluar transport. Long term treatment with chenodeoxycholic acid for gall stone dissolution may therefore affect gall bladder func- tion leading to an accumulation of lipid in the mucosa as seen in cholesterolosis.

Thanks are due to the surgeons of Ninewells Hospital who provided cholecystectomy samples. This work was funded by a project grant from The Scottish Home and Health Department.

1 Thomson ABR, Dietschy JM. Intestinal lipid absorption: major extracellular and intracellular events. In: Johnson LR, ed. Physiology of the gastrointestinal tract. New York: Raven Press, 1981:1147-1220.

2 English M, Hopwood D. Lipids in the human gall bladder mucosa. J Pathol 1985;146:333.

3 Ross PE, Bakar M, Jacyna MR, Hopwood D, Shepherd AN Bouchier IAD. Does the gallbladder modify biliary lipid composition? In: Elias E, Murphy G, eds. Bile in health and disease. Proceedings of the British Society of Gastroenterology. 1985. Welwyn Garden City: Smith Kline and French, 1986:51-3.

4 Neiderhiser DH, Harmon CK, Roth PH. Absorption of cholesterol by the gall bladder. J Lipid Res 1976;17: 117-24.

5 Ross PE, Azman M, Hopwood D, Shepherd AN, Ramsay A, Bouchier IAD. Lipid absorption by human gallbladder. Ann NY Acad Sci 1986;463:344-6.

6 Jacyna MR, Ross PE, Bakar MA, Hopwood D, Bouchier IAD. Characteristics of cholesterol absorption by human gall bladder: relevance to cholesterolosis. J Clin Pathol 1987;40:524-9.

7 Watanabe M, Oku T, Shidoji Y, Hosoya N. A new aspect on the mechanism of intestinal cholesterol absorption in rats. J Nutr Sci Vitaminol 1981;27:209-17.

8 Hayward AF. Electron microscopic observations on absorption in the epithelium of the guinea-pig gallbladder. $Z$ Zellforsch 1962;56:197-201.

9 Elhamady MS, Milne G, Hopwood D, Ross PE, Bouchier IAD. The uptake of cationised ferritin by guinea-pig gallbladder in vitro. Histochem $J$ 1984;16:275-85.

10 Jacyna MR, Ross PE, Gallacher C, Hill A, Hopwood D, Bouchier IAD. Absorption of non-absorbable markers and an improved method for determining cholesterol absorption rates. Br J Exp Pathol 1988;69:23-33.

11 Dawson RM, Elliott DC, Elliott WH, Jones KM. Data for biochemical research. 2nd ed. London: Oxford University Press, 1969:507.

12 Thomas PJ, Hofmann AF. A simple calculation of the lithogenic index of bile; expressing biliary lipid composition on rectangular co-ordinates. Gastroenterology 1973;65:698-700

13 Herberg RJ. Statistical aspects of double isotope liquid scintillation counting by internal standard technique. Anal Chem 1964;36:1079-82.

14 Folch J, Lees M, Sloane-Stanley GH. A simple method for the isolation and purification of total lipids from animal tissues. J Biol Chem 1957;226:497-509.

15 Murison J, Festi D, Ross PE, Bouchier IAD. The estimation of phospholipids in bile. Clin Chim Acta 1976;68:159-66.

16 Bateson MC, Ross PE, Murison J, Bouchier IAD. Effect of prolonged feeding with chenodeoxycholic acid on bile in patients with and without gallstones. Gut 1977;18: 599-605.

17 Carey MC, Small DM. Micelle formation by bile salts. Physical-chemical and thermodynamic considerations. Arch Int Med 1972;130:506-27.

18 Watt SM, Simmonds WJ. Effects of four taurine-conjugated bile acids on mucosal uptake and lymphatic absorption in the rat. J Lipid Res 1984;25:448-55.

19 Watt SM, Simmonds WJ. The specificity of bile salts in the intestinal absorption of micellar cholesterol in the rat. Clin Exp Pharmacol Physiol 1976;3:305-22. 